Stokoe, Elizabeth, Huma, Bogdana

ORCID: https://orcid.org/0000-0003-0482-9580, Sikveland, Rein Ove and Kevoe-Feldman, Heidi (2020) When delayed responses are productive: Being persuaded following resistance in conversation. Journal of Pragmatics, 155. pp. 70-82.

Downloaded from: http://ray.yorksj.ac.uk/id/eprint/4117/

The version presented here may differ from the published version or version of record. If you intend to cite from the work you are advised to consult the publisher's version: https://www.sciencedirect.com/science/article/pii/S0378216619306290

Research at York St John (RaY) is an institutional repository. It supports the principles of open access by making the research outputs of the University available in digital form. Copyright of the items stored in RaY reside with the authors and/or other copyright owners. Users may access full text items free of charge, and may download a copy for private study or non-commercial research. For further reuse terms, see licence terms governing individual outputs. Institutional Repository Policy Statement

\title{
RaY
}

Research at the University of York St John

For more information please contact RaY at ray@yorksj.ac.uk 


\section{When delayed responses are productive: Being persuaded following resistance in conversation}

Elizabeth Stokoe ${ }^{1}$ (corresponding author), Bogdana Humă², Rein O. Sikveland $^{1}$, \& Heidi Kevoe-Feldman ${ }^{3}$

${ }^{1}$ School of Social Sciences and Humanities, Loughborough University,

Epinal Way, Loughborough

LE11 3TU

UK

e.h.stokoe@lboro.ac.uk / r.o.sikveland@lboro.ac.uk

${ }^{2}$ School of Psychological and Social Sciences,

York St John University,

Lord Mayor's Walk,

York

YO31 7EX

UK

b.huma@yorksj.ac.uk

${ }^{3}$ Communication Studies,

College of Arts, Media and Design,

Northeastern University,

360 Huntington Ave

Boston

MA 02115

USA

H.KevoeFeldman@northeastern.edu

FINAL DRAFT ACCEPTED OCT 2019 


\title{
When delayed responses are productive: \\ Being persuaded following resistance in conversation
}

\begin{abstract}
Conversation analysts have long since demonstrated that, in responding to an initiating action (e.g., question), recipients have at least two ways to respond; that response options (e.g., answer, non-answer) are not equivalent, and that 'preferred' responses are typically delivered more rapidly than 'dispreferred' responses. This paper examines cases in which 'preferred' responses, which progress the preceding actions in productive alignment, are delayed. We combined and analysed four British and American datasets: mediators talking to potential clients; police negotiators talking to suicidal persons in crisis; calls to emergency services from suicidal persons, and salespeople talking to potential customers. Our analysis revealed that, when one party has resisted the project of the other, delay may indicate an upcoming productive response. Such delays break the sequence's contiguity, thus producing (some) structural independence from a previously dismissed course of action and enabling the speaker to maintain (some) 'face', in Goffman's terms. We discuss the implications of these findings for understanding alignment and preference in conversation analysis, and the practices of resistance and persuasion more generally.
\end{abstract}

Keywords: Preference organization; alignment, progressivity, conversation analysis; persuasion; resistance; negotiation; sales. 


\subsection{Introduction}

When do speakers delay producing a productive response - that is, one which is aligned to and progresses the course of action initiated in the preceding turn?

Conversation analysts have previously established that, in responding to an initiating action by one speaker (e.g., question), their interlocutor has at least two ways to respond, and that response options (e.g., answer, non-answer) are not equivalent. This inequality has been pursued in terms of the concept of 'preference', which refers to the "range of phenomena associated with the fact that choices among nonequivalent courses of action are routinely implemented in ways that reflect an institutionalized ranking of alternatives" (Atkinson and Heritage, 1984, p.53). Crucially, 'preference' is structural, not normative or psychological (Schegloff, 2007). However, as Bilmes (1988) pointed out, "Preference is treated as a single concept in conversation analysis, but it has in fact developed into an assemblage of loosely related concepts" (p.161; emphasis in original; see also Boyle, 2000, on the evolution of preference and its interpretation). In describing the structural and sequential properties of 'preferred' and 'dispreferred' responses, related concepts such as (dis)alignment and (dis)affiliation have all been brought to bear on the more general notion of progressivity, which refers to the way every turn at talk progresses or impedes ongoing courses of action (e.g., Stivers, 2008).

An enduring observation about the preference organization of turns at talk is that preferred responses - those which are aligned to the prior, and progress the action it has initiated - what we refer to as productive responses - have been shown to be delivered more rapidly than dispreferred responses (Schegloff, 2007). However, our focus in this paper is on interactional environments in which productive 
responses are delayed; that is, sequences of talk in which a speaker supplies a delayed response that, nevertheless, progresses a previously resisted overarching conversational project. The datasets (all English-speaking) are recordings of apparently diverse settings: police negotiators talking to suicidal persons in crisis; calls to emergency services from suicidal persons; mediators talking to potential clients, and salespeople talking to potential customers. What these settings share, however, is an initial divergence of participation and conversational goal in which one party (the person in crisis; the potential customer or client) finds themselves in an interaction they did not seek and possibly do not want. The other party's goals (police negotiator; mediator, or salesperson) are to persuade their interlocutor to do something opposite to their displayed 'intent' (stop the person in crisis committing suicide) or sought-out needs (engage in mediation; meet a salesperson).

We will show that, after sequences in which one party actively and explicitly resists the project of the other, subsequently productive responses are routinely delayed. For example, after maintaining a stance of intent to commit suicide, persons in crisis may delay their responses which indicates they will not carry out their initially intended act. In customer-sales encounters, having resisted initial requests to meet a salesperson, potential customers delay agreement to meet. We show that 'persuaded' turns at talk may, therefore, be delayed, and that moving to a shared alignment with the other party happens stepwise across sequences of actions rather than, say, in one adjacency pair or turn. This is because to immediately agree to a police negotiator's first request to 'come down' (or to move to safety, or otherwise alleviate the threat of harm to self or others) challenges the integrity of the person threatening suicide; saying 'yes' to a salesperson could imply naivety and exploitability for a customer. By delaying a response which contradicts a previously 
taken stance, individuals pre-empt 'losing their face' (Goffman, 1967) as the result of being deemed inconsistent or easily persuadable.

We start with an overview of existing literature on preference and delay, before moving into the main empirical part of the paper.

\subsection{Preference organization and delay}

'Preference' and 'preference organization' are cornerstone concepts in conversation analysis, introduced in Sacks's (1992) lectures, much written about, and often quoted and used to comment on data both by those at the core and at the fringes of the discipline. Preference organization is a feature of turn design, action organization, and the sequential organization of turns. The basic organization of a sequence of action is the 'adjacency pair', comprised of two turns, one after another, which are type-connected (Schegloff and Sacks, 1973; Sacks, 1987). The significance of this organization is that, for a first pair part action (e.g., offer, request, invitation), there are, for some actions, alternative types of fitted responses that could constitute a second pair part response. For example, an invitation could get an acceptance or rejection. Another important feature of preference, taken up by Pomerantz and Heritage (2012), is how speakers design turns in a way that can exhibit preferences (e.g., responses to yes/no questions) and perform actions such as compliments, which tend to get a downgraded response rather than acceptance (Pomerantz, 1978). Thus, preference organization is one mechanism participants may deploy to avoid or minimize disagreement, rejection, disconfirmations, and so on, thereby maintaining relationships and promoting social solidarity (Pomerantz and Heritage, 2012). 
Sacks's initial work led to an enduring technical observation in conversation analysts' research on preference and the progress of sequences: that preferred second pair part responses are produced more rapidly than dispreferred ones, while dispreferred responses are projected by, amongst other features, an inter-turn gap (Davidson, 1984; Pomerantz, 1984; Pomerantz and Heritage, 2012). Another way of describing this is that preferred responses immediately progress the course of action, while dispreferred ones temporally disconnect the two actions. More recently, Kendrick and Torreira (2015) have further specified these classic findings by demonstrating that the inter-turn gap between a first and a second pair part pertains to a dispreferred turn design, rather than a dispreferred action. They also found that, in fact, the majority of preferred and dispreferred actions have a delayed onset of up to $300 \mathrm{~ms}$. Either way, what an inter-turn gap 'means' is a members' orientation (Stokoe, 2018). For example, "enacting the onset of a disagreement or rejection in a delayed manner gives the person who initiated the sequence options to modify his or her prior talk or action. ...Through the participants' collaborative activities, explicit rejections thus are minimized or avoided" (Pomerantz and Heritage, 2012, p. 215-6). Pomerantz (1984) provides a clear case.

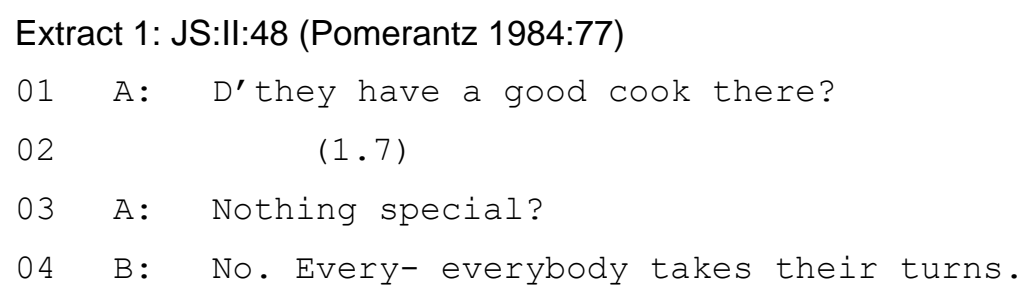

Pomerantz points out that A treats the silence at line 02 as a "disagreement in the course of production, that is, unstated, or as yet unstated, disagreements" (p. 76). 
Thus, by taking the next turn, $\mathrm{A}$ formulates a new question that reduces the distance between her stance and her interlocutor's, which the latter then agrees with.

That inter-turn gaps (or delay, or silence) can indicate an upcoming dispreferred response can be found in both real and scripted talk. In The Duchess, a film based on a biography of aristocrat Georgiana Cavendish, the Duchess is talking to Charles Grey (Prime Minister of Great Britain in the early $19^{\text {th }}$ century), with whom she is having an affair.

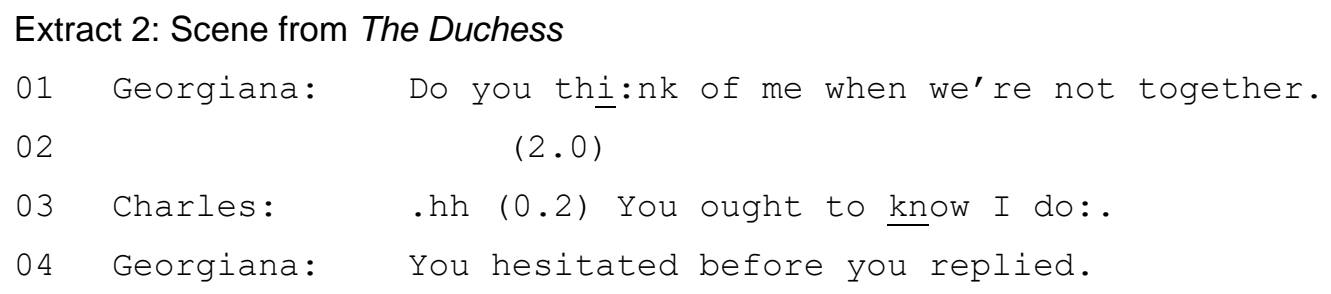

Georgiana asks her lover a question. It is a yes/no interrogative; a type-conforming response would be 'yes' or 'no'. The script illustrates the point made earlier that these are not, however, equivalent. After a two-second delay, Charles replies, "You ought to know I do:." His response implies that Georgiana did not need to ask this question. She should take for granted the fact that he thinks of her when they are apart. Yet Georgiana's next response, "You hesitated before you replied", highlights the implications carried in delay of a dispreferred response.

In unscripted dialogue from the British television show, Location, Location, Location, the hosts are two property-hunters, Phil Spencer and Kirsty Allsopp. They help house-hunters find a property to buy. Phil and Kirsty show the house-hunters several properties in different locations, during each episode. In Extract 3, Phil is asking a couple, Suzie and Andy, if they know the town where the next property to be viewed is located. 


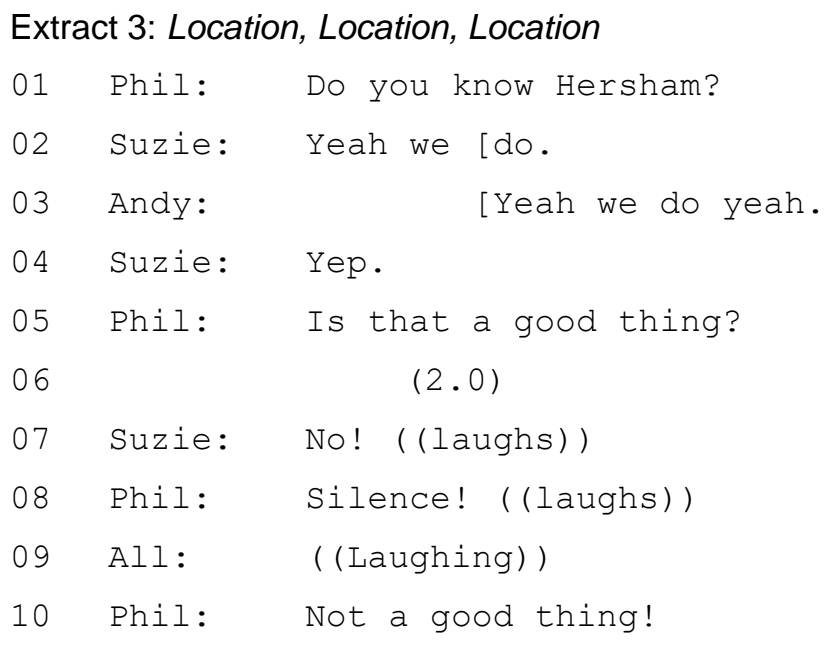

Suzie and Andy respond rapidly and positively to Phil's first question, "Do you know Hersham?" with a series of "yeahs". But a two-second delay follows Phil's follow-up yes/no interrogative, "Is that a good thing?" Again, this two-second delay correctly predicts an upcoming dispreferred response; one that does not progress the overall course of action that the parties are involved in. Phil shows his understanding that delay indicates an upcoming dispreferred response: he formulates the couple's delay (“Silence!") and makes explicit what it means ("Not a good thing!").

A first attempt at quantifying the length of inter-turn gaps was made by Jefferson (1989). In her English-speaking data, from telephone and face-to-face settings, inter-turn gaps ranged from 0.2 to 3.4 seconds. While silence durations are variable, she observed that speakers, after one second of silence, routinely (i.e., across the 320 instances in her collection) initiate some new activity designed to resolve whatever is the issue with their preceding turn. Based on these observations she proposed a 'standard maximum allowance for silence' (see Hepburn and Bolden, 2017), which excluded cases where silences are otherwise accounted for, such as instances of some non-conversational activity (e.g., writing down a telephone number). We note that, in both Extracts 2 and 3, the silences are longer than one second; in our upcoming analysis we present inter-turn gaps ranging 
between 1.2 and 3.0 seconds. Whether and how a 'standard maximum' is attended to, we may still observe how speakers orient to any and all inter-turn gaps and silences in sequence and action terms. And, certainly, longer inter-turn gaps like those in Extracts 2 and 3 are indicative of dispreferred actions, or at least of actions packaged within dispreferred turn formats.

The differentiation between the action implemented by a turn, such as accepting or rejecting an invitation, and the design of that turn, as preferred or dispreferred, allows us to discern bald rejections (dispreferred actions, delivered with preferred formats) and qualified acceptances (preferred actions delivered with dispreferred formats). According to Kendrick and Torreira (2015, p. 273), the latter "qualify or mitigate the speaker's commitment to the action and thereby formally resemble dispreferreds". While the delayed responses we examine fall within the 'qualified acceptance' category, we are interested in how the inter-turn gap - the first virtual component of dispreferred turn design - is mobilized as a resource by interactants who begin to produce a productive response after having previously resisted the same course of action.

Thus, speakers in second position have available to them a set of resources that particularize the responsive actions implemented by their turns. For instance, responding to yes/no interrogatives with yes/no (type-conforming) formatted turns exhibits both alignment to and acceptance of the terms proposed by the questioner. By contrast, a non-type-conforming reply can answer the question while treating it as somehow inapposite (Raymond, 2003). In Danish, recipients of remote requests can signal, using modal adverbs, that their acceptance to carry out the requested action is done reluctantly, out of obligation or as a concession (Steensig and Heinemann, 2015). Speakers can resist the constraints put forward by initiating actions by providing transformative answers which rework the terms or the agenda of the 
questions (Stivers and Hayashi, 2010). A wealth of conversation analytic research has documented the crucial role of turn-initial particles in second pair parts in shaping courses of action from second position by adjusting their direction, challenging assumptions imbedded in first pair parts, or renegotiating interactants' relative epistemic positions (Bolden, 2009; Heritage and Sorjonen, 2018).

The notion that delay indicates an upcoming dispreferred response has, in some ways, passed out of the realms of empirical reality and, like other communication myths, become something we 'just know' about interaction (Stokoe, 2018). This may be in part because the original research and its recycling in textbooks focused on delayed dispreferred responses. However, delays may precede an upcoming productive second pair part, promoting it as an action done reluctantly (e.g., Bilmes, 2014), or non-committedly (e.g., Kendrick and Torreira, 2015). Relatedly, several authors have also shown that the structural organization of preference is reversed in sequences of conflict, with dispreferred responses (e.g., disagreements) occupying a preferred turn shape and vice versa - the order of preference organization is revealed 'in the breach'. The re-establishment of 'usual' preference orders is core to the onset and resolution of conflict. For instance, Garcia (1991) pointed out that, in her study of disputes in mediation hearings, the 'preferred' response to an accusation is a denial and are "produced without the delay that might allow accusers to repair or mitigate accusations" (p. 821). Similarly, Kothoff (1993) writes that, once underway, sequences of argument are identified by the fact that "it is no longer preferred to agree. On the contrary, it seems very important to contradict quickly and in a coherent manner" (p. 203).

In Bella and Moser's (2018, p. 96) study of impromptu invitations "triggered by means of polar negative-interrogatives in Greek" (in contrast to reason-for-the-call invitation sequences), they found that the preferred response of acceptance was 
often delayed. Bella and Moser ground their explanation for delayed acceptances "in the conflicting preferences built in the polar negative-interrogative construction when used to issue impromptu invitations" and that "[i]nvitees exploit the delayed acceptance pattern as an interactional solution for cross-cutting preferences" (p. 96). For instance, in response to one speaker's (Yannis) invitation "Wouldn't you come tomorrow to see the game?", Nikos's immediate response is delayed by 0.3 seconds, and his eventual acceptance ("Ok") occurs after asking several questions about where they will do the watching, who else will be there (Nikos is concerned that Yannis should check with his girlfriend before issuing the invitation). Finally, Yannis issues a new first pair part: "The game starts at eight. Come around seven to chat a bit"', to which Nikos produced a preferred response: "Ok. Do you want me to bring something" (p.105-6). Unlike the studies of disputes in talk mentioned above, Yannis and Nikos are not 'in conflict' in the sense of argumentation, though their actions were not immediately aligned after the first invitation was launched. Summarizing this analysis, Margutti et al $(2018$, p.58) explain that such delayed acceptances follow a "negotiation sequence in which the invitee exhibits hesitation", which leads inviters to "re-issue the invitation". This is relevant to our upcoming analysis, not only because preferred responses come after a series of previously dispreferred ones, but also in that the initiating actions (compare the negative interrogative first invitation to the imperative second) may be produced by different grammatical vehicles. Furthermore, what counts as a 'preferred' response is scalar; in this case, Nikos's "Ok" is not an upgraded assessment of the prior turn (e.g., "Great!"). This brings us back to Bilmes's (1988) observation, noted at the start of the Introduction, that 'preference' comprises "assemblage of loosely related concepts" (p.161), including 'alignment'. 


\subsection{Preference and (dis)alignment}

While preference organization constitutes a set of overarching principles that speakers orient to and abide by (Pillet-Shore, 2017; Pomerantz and Heritage, 2012), it may be useful to consider the relationship between preference and alignment. Traditionally, the labels preferred/dispreferred responses are applicable only within adjacency pairs, whereas analysts typically refer to (dis)aligned responses across a series of adjacent turns within larger sequential structures such as story-tellings (Stivers, 2008) or troubles-tellings (Jefferson and Lee, 1981). While preference implies a binary dimension, alignment may be conceived as a continuum, with responses to preceding actions being more or less productive. Furthermore, alignment has been used to refer to whether a response accepts the presuppositions and terms contained in the initiating action. Thus, we can distinguish between a preferred aligned response, such as an upgraded second assessment (Pomerantz, 1984), and a preferred but less aligned response, such as an oh-prefaced second assessment, though which the speaker claims epistemic primacy over the assessed object (Heritage and Raymond, 2005).

The terms preference and alignment have been also used to characterize features of the design of a responsive turn; that is, the grammatical fittedness between a second and first pair part. In terms of grammar, we refer to typeconformity, not only for yes/no interrogatives and yes/no prefaced responses, but more generally in terms of responding to what the first pair part is asking (see Stivers and Hayashi, 2010, on transformative responses). As we will see, some second pair parts (e.g., "Go on", or "I'm not gonna jump") are preferred in 'action' terms in that they announce that the speaker will move forward towards a shared goal with their interlocutor, but dispreferred and disaligned (grammatically unfitted).Thus, following 
Kendrick and Torreira (2015), we distinguish between the design (grammar) and the action implemented by a responsive turn. We treat 'delay' as a feature of the turn's design while using the term 'productive' to refer to the range of aligned and/or preferred responsive turns that contribute to the accomplishment of the first pair part's action and maintain progressivity. That is, we examine sequences of talk in which productive responses are supplied in the format that conversation analysts have generally regarded as belonging to dispreferred responses, and in cases where agreement, confirmation, and acceptance are delayed.

The paper extends our understanding of the stepwise shift from disalignment to alignment and how delayed responses feature in that realignment. In contrast to couples' conflict, disputes in institutional settings, or other contexts in which analysts have convincingly challenged a straightforward mapping of delay onto dispreference, we examine how delayed responses productively progress encounters that, from the outset, normatively partition the parties and involve the 'face' constraints associated with changing one's mind.

\subsection{Data and method}

Four datasets provide the empirical materials for our research. The first three were all recorded in the UK and the participants speak British English. The first dataset comprises approximately 300 initial inquiry calls and call-backs to and from five family and five community mediation services. These data were collected between 2005-15 as part of an UK research council-funded study of neighbour disputes. All participants consented to their conversations being recorded; consent was gained via the call-taker formulating an 'ethics script' that was negotiated with the 
researcher. As is common practice in studies of professional-client interaction, information about the project and informed consent was supplied, but the actual wording was left to the professional to manage. The second dataset is a corpus of 150 business-to-business prospecting 'cold' calls - unsolicited, salesperson-initiated telephone conversations - from four UK companies that provide one of the following: multifunctional printers, telecommunication systems, or advertising services. The data were supplied by the companies, who routinely record calls for 'training and quality purposes.' In these encounters, call-takers are employees of various UKbased organisations.

Third, a UK police Hostage and Crisis Negotiation Unit supplied audio recordings of interactions between people in crisis and negotiators, recorded at the scene in 2016 as a routine part of their job. Fourteen cases were provided for a study of crisis negotiation, totalling 31 hours of data. Negotiations are usually led by one negotiator, who is supported by a team of three other negotiators. Interactions sometimes took place on the telephone and sometimes face-to-face (often at a distance). Police refer to their interlocutors as 'persons in crisis', and we use their term in this paper. Finally, we also analyse cases from a subset of American-English emergency call centre calls ('911'). As part of the authors' ongoing research into crisis negotiation (e.g., Sikveland, Kevoe-Feldman and Stokoe, 2019), we identified eight calls from people reporting suicidal ideation or intent.

Ethical approval was secured on behalf of the Hostage and Crisis Negotiation Unit who supplied that data. Like police interviews of suspects and witnesses, recordings were already made by police in situ, as part of routine work practice. They were provided to us after the possibility of formal consent (pre or post-hoc) could be granted, and on the basis that they were used anonymously and stored according to the usual standards for university research data management (i.e., under 
encryption). The US data set received IRB human subject approval from a University Ethics Committee, which includes an approval letter to use the data for training and research from the participating State Police.

All calls in the datasets were initially transcribed verbatim before extracts containing our analytic phenomenon were transcribed using the conversation analytic system (Hepburn and Bolden, 2017). All transcripts were anonymized: we modified all first names and surnames of persons, their telephone numbers, email, and other addresses. The data were analysed using conversation analysis (CA). Starting with a technical transcript of the recorded data, CA proceeds by repeatedly viewing or listening to the data and transcript, and demonstrates, by analysing the organization of conversation turn by turn, how the design of an activity (e.g., requests, complaints, instruction) places constraints on the ways that responses can be made. We draw on CA's principles of turn design, action formation, and sequence organization which served as a methodological framework (Sacks, 1992; Schegloff, 2007).

What ties our datasets together is that they all involve conversations that we might gloss as 'reluctant', in that one party (the mediator, salesperson, negotiator, or emergency call-taker) must interact with someone whose participation is, at the very least, not straightforward. In mediation calls, people in disputes phone for help having failed to resolve matters. Although some initiate encounters, seeking help, they do not call to make appointments with mediators. Rather, they call mediation having tried somewhere else first (e.g., the police, lawyers, council authorities) - and are now calling a service they do not know about and did not initially want. Furthermore, mediators then make what are effectively 'cold' calls to the other party in the dispute. In sales calls, salespeople call potential clients who have not initiated or requested any such conversation. In the crisis negotiations and emergency 
services calls, the issue of who wants the conversation is moot. We may see someone who calls as 'crying for help', and people who make themselves physically possible to talk to (and do not 'just' commit suicide on their own, without the possibility of discovery or negotiation) as 'wanting' the conversation. But this is not an easy claim to warrant from the data themselves. In other words, it is not the case that people just agree to cooperate with negotiators, to make a sales appointment, or to participate in mediation.

\subsection{Analysis}

Across two sections of analysis, we examine extracts from our data in which one speaker produces a productive response that constructs and progresses an aligned trajectory between speakers following previous disalignment. The extracts presented are selected from all instances of delayed productive responses identified across the datasets. In each case, the productive response follows an inter-turn gap, or delay. One benefit of the term 'productive' responses is to deal with potentially 'psychological' notions of preference. For example, crisis negotiators, mediators, and salespersons, and their interlocutors, have divergent interactional goals as inscribed in their discourse identity (Zimmerman, 1998), displayed through their spoken turns or, in the case of crisis negotiation, simple physical dislocation (on the ground versus on a roof). In each case, the speaker initiating the project pursues a productive response by redesigning initiating actions, often by formulating some proposition the recipient can more readily align with (see Davidson, 1984 on subsequent versions of proposals; see also Bella and Moser's 2018 analysis of delayed acceptances of invitations, summarized earlier). 
As we progress through the analysis, we will show that a binary notion of preference is less useful than more macro, cross-sequence notions of alignment and progressivity, when it comes to understanding how delay works in these transformative sequences. Speakers may produce strongly unproductive, dispreferred turns in terms of the local adjacency pair as well as disaligned responses in terms of the broader course of action. Across sometimes hours-long episodes of negotiation, particularly in crisis conversations, stepwise movements between (dis)alignment occurred multiple times. We will encounter cases in which second pair parts comprise active resistance with explicit forms of disalignment, but on a continuum in terms of strength of stance (e.g. "it sounds like a waste of time" versus "I don't want any help").

\subsection{A preliminary case of a delayed productive response}

We start with an extended case. Extract 4 comes from a call from a family mediator (M) to a prospective client $(\mathrm{C})$; the mediator has initiated the encounter and mediation, as a service, has not been sought by $C$. In fact, $M$ has called $C$ regarding an invitation to mediation that the service has previously sent via letter, to which the caller has not responded. As we will see, following the mediator's explanation of her reason for calling - to follow up on the letter's invitation $-\mathrm{C}$ resists participating. It provides our first case of a delayed response that is productive, in terms of both parties aligned to the activity of mediation, following turns that resist or are in other ways disaligned to the initiating actions of the mediator. The extended extract exemplifies stepwise progress from disalignment to alignment; from impeded to productive progress. 


\section{Extract 4: DG-30, 1:00-2:11}

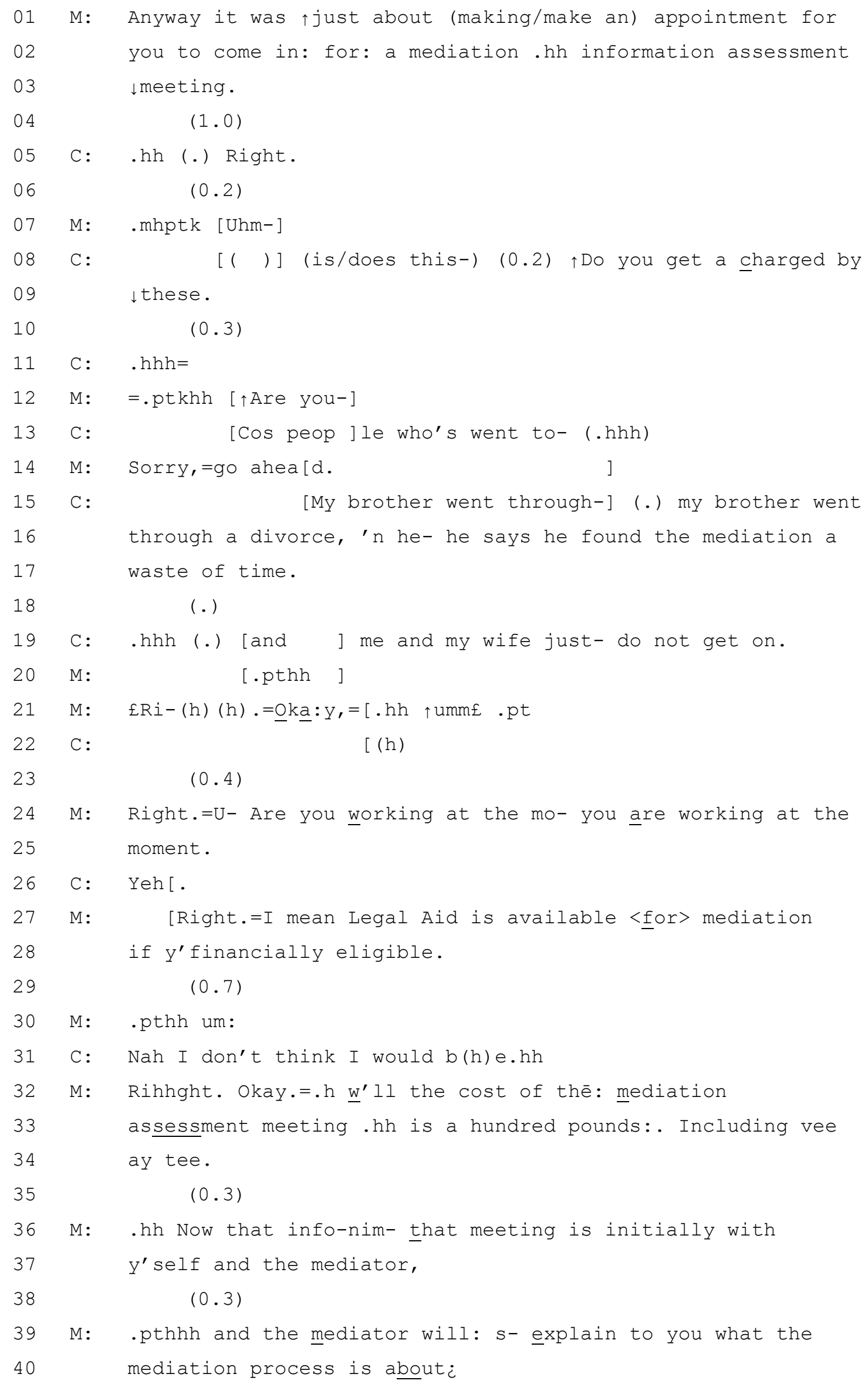




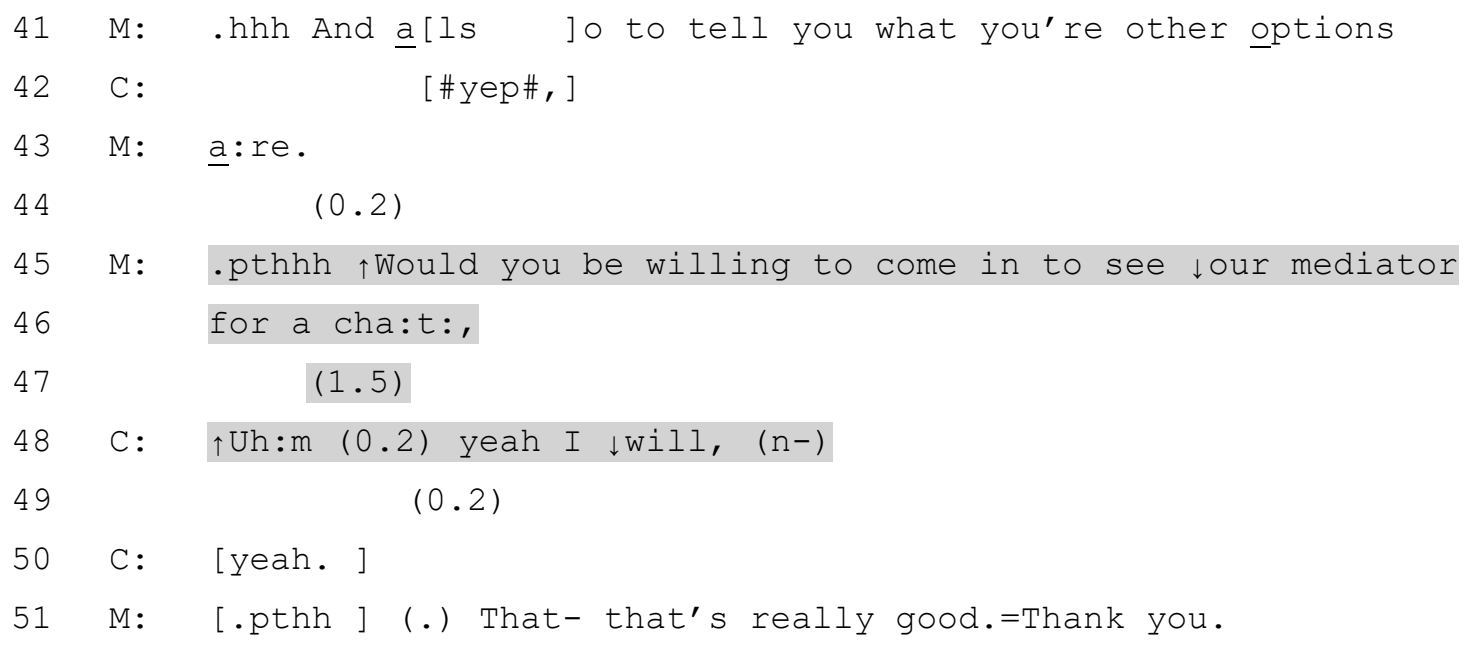

At the start of the extract, after $\mathrm{M}$ summarizes the reason for the call, we can already notice the weak or resistant uptake from $C$ in line 04 , in which a one second gap develops before $\mathrm{C}$ responds with an inbreath and "right.." Here, the gap indicates this upcoming disalignment. At lines 08-09, $\mathrm{C}$ begins building his case for resistance by inquiring about the charge for this service. While $\mathrm{M}$ begins an insert expansion sequence to establish whether $\mathrm{C}$ would pay for mediation, C, in overlap, articulates further pre-emptive accounts for not engaging in mediation (line 13). Furthermore, according to C's brother, mediation is a "waste of time" (lines 15-17). C goes on to apply this third-party opinion to his own situation in line 19: "and me and my wife justdo not get on." A gloss of his turns amounts to 'it didn't work for my brother, and it definitely won't work for us either'. So far, then, $\mathrm{C}$ seems a long way from agreeing to mediate.

After a rapid confirmation that he is 'working' (line 25), which M asks as a prequestion to establish his eligibility for receiving financial aid for mediation, C's turns and absence of aligning (Stivers, 2008) responses (e.g., continuers) throughout M's introduction to legal aid eligibility and a process-based summary of the initial mediation meeting suggests further, though more tacit, resistance (e.g., lines 29, 35, $38,44)$. However, at line $45, M$ asks "Would you be willing to come in to see $\downarrow$ our 
mediator". After a 1.5 second inter-turn gap (line 47), plus further hesitation and a pause that delays his response, C says "yeah I $\downarrow$ will,". This turn contains classic features of dispreference, but it is nonetheless a preferred response: it is productive in progressivity terms; produces alignment between the parties, and displays commitment to M's remote request (Lindström, 2017) to see a mediator. Here, the delay temporarily separates C's preferred response from M's request. This may be akin to a reluctant agreement; one that has been the product of persuasion. $\mathrm{C}$ has shifted his stance from incipient 'no' to 'yes', and the parties are now more closely aligned with regards to the overall project of making an appointment for mediation.

The case above is interesting when compared to earlier research by Stokoe (2013), who found that some lexical choices impacted prospective clients' 'willingness' to agree to mediation. Sikveland and Stokoe (2016) discovered that callers were more likely to agree to mediate when asked about their 'willingness' than, say, about their 'interest' in mediating. In Extract 4, the prospective client agrees to mediate following a question about their 'willingness' to do so, but through turn design features more typical of a dispreferred, disaligned response. To change one's mind while maintaining 'face' (Goffman, 1967) or, as discursive psychologists might put it, a credible, authentic identity (e.g., Edwards, 2005), is a delicate matter. In Extract 4, the client maintains 'face' by delaying their newly productive stance towards mediation, albeit one produced as reluctant, persuaded, or acquiescing. We examine further cases in the next section.

\subsection{Further cases of delayed productive responses}

Having analysed our first case, we move on now to examine a series of examples from other settings, starting with Extract 5 from a police negotiation with persons in 
crisis. We join the negotiation 90 minutes since its start. The person in crisis (PiC) has resisted the negotiator's $(\mathrm{N})$ proposal to 'come down' and follow them to the police station. PiC has previously been involved with social services but now, because he has turned eighteen years old, he is no longer eligible for their support. $\mathrm{He}$ is concerned that his situation will worsen by agreeing to come to the police station. There is some inaudible talk from the $\mathrm{PiC}$, but it is clear that he is building a case against support proffered by another negotiator. The focus of our analysis starts with the explicit rejection of help at line 08 .

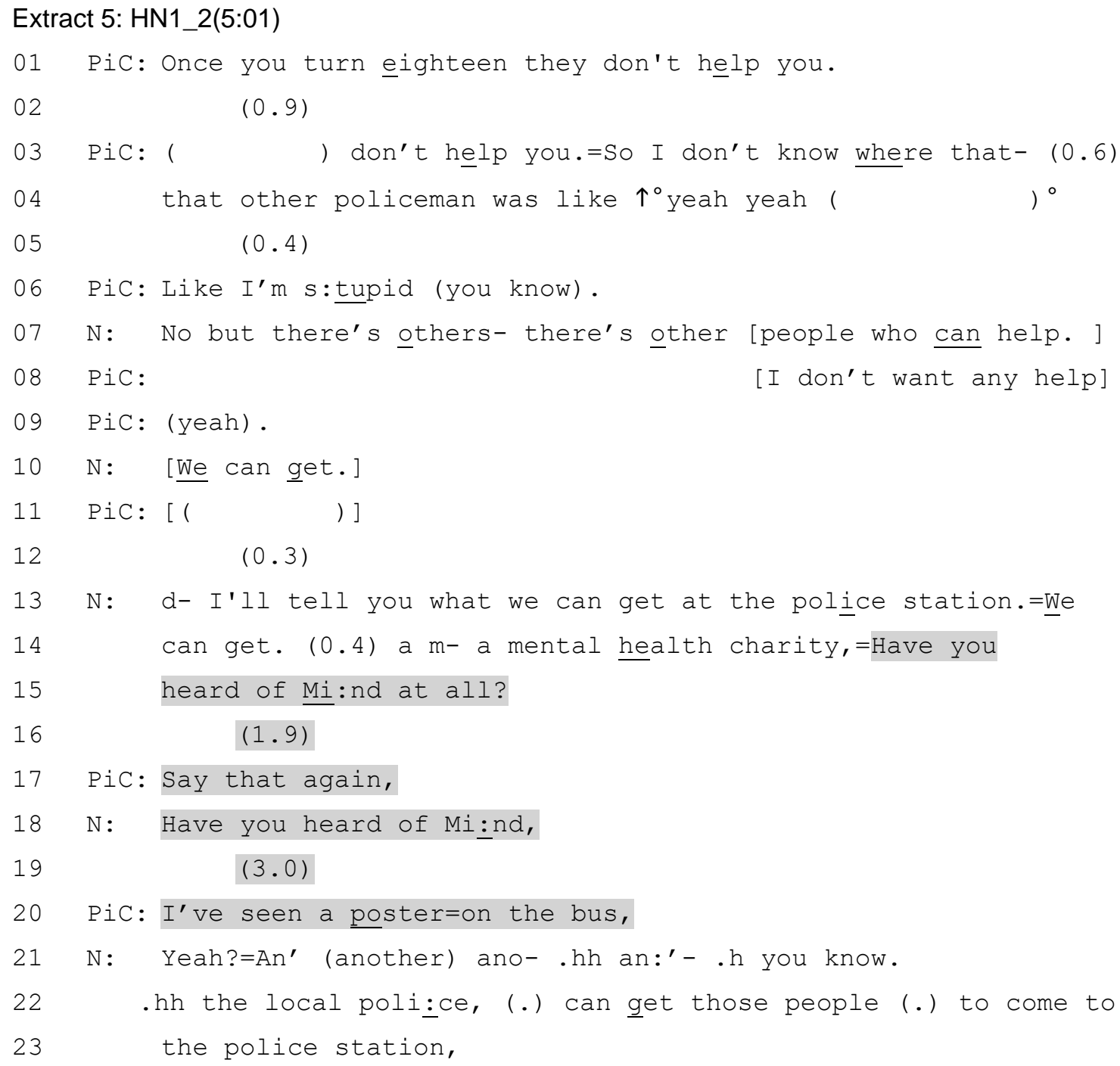


PiC's delayed response at line 20 fits our emerging analysis of the way in which shifting stance, from one strongly stated position (that is contrary to one's interlocutor) to a different position (that is aligned to one's interlocutor), is done stepwise. The PiC is building a case against proffered support from "that other policeman", arguing that he is not eligible for such support and is more knowledgeable about his entitlement than the officer (lines 01-06). At line 07, N begins with "No", agreeing with $\mathrm{PiC}$ that he knows about his own eligibility for support, before continuing the turn by beginning to make further suggestions "but there's others- there's other people who can help." At line 08, PiC resists N's suggestion before it is complete, talking in overlap and displaying early understanding of N's action and attempting to halt its production. He resists the emerging offer of help explicitly: "I don't want any help". The two continue in overlap until the gap at line 12 .

At line 13, N begins a new offer "d- l'll tell you what we can get at the police station.", the repair initiator at the start perhaps abandoning a yes/no interrogative pre-sequence ('do you know...') and instead delivering a declarative formatted preliminary turn (Schegloff, 2007), launching a new sequence. $\mathrm{N}$ specifies alternative support with the mental health charity Mind, with a yes/no question, "Have you heard of Mi:nd at all?" At line 16, a gap of 1.9 seconds opens up, before PiC issues a repair initiator, "Say that again," (line 17). This first delay, while preceding a repair initiator, nonetheless constitutes a request to redo an initiating action, rather than continue to resist whatever the $\mathrm{N}$ does. $\mathrm{N}$ repeats the question, treating $\mathrm{PiC}$ 's repair initiator as indexing a problem of hearing.

After a longer gap, this time 3.0 seconds, $\mathrm{PiC}$ answers the question, albeit rather obliquely. By specifying he knows about Mind from a bus poster, he informs $\mathrm{N}$ that, while he is aware of this organization, he only has limited knowledge about it - 
as much as one could presumably get from a poster. Nonetheless, $\mathrm{PiC}$ is no longer actively disaligned to the course of action initiated by $\mathrm{N}$ at line 15 , in contrast to his objections previously to suggestions for help. His response is substantially delayed, unlike his earlier dispreferred turns which are delivered rapidly and in overlap. Indeed, “I don't want any help" does not contain other markers of dispreference, such as hesitation, an account, or an appreciation.

Extract 6 provides a further instance, from a different crisis negotiation, of the way a repair initiator may co-occur with a delayed response at the point of incipient alignment shift. PiC has produced successive dispreferred responses that halt the progress of the negotiation, and particularly N's requests to talk to PiC. Here, $\mathrm{N}$ has been attempting to trade cigarettes for PiC's participation.

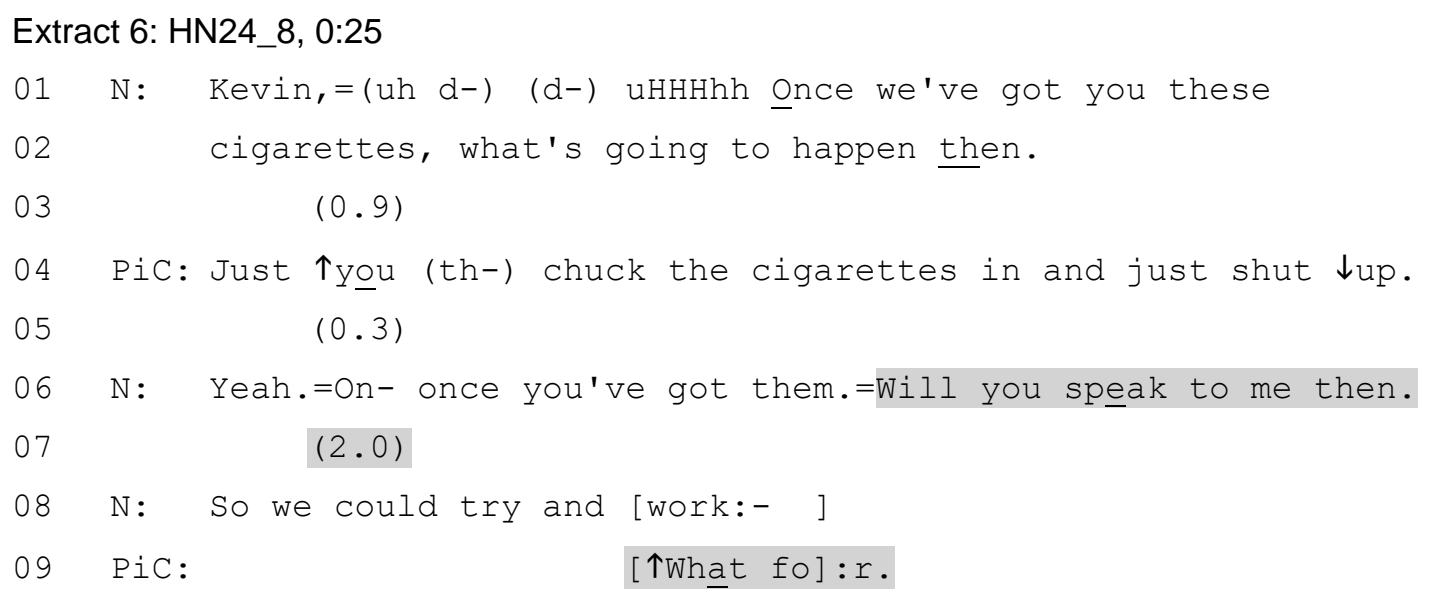

In response to N's wh-question (lines 01-02); PiC's response is fitted neither in terms of form or function, and so does not progress the terms of discussion set out in N's question, requesting that N 'chuck' (throw) the cigarettes and "shut up". However, in response to N's subsequent new action - a yes/no interrogative request to speak PiC (in overlap) produces a delayed repair initiator (“个What fo:r.”). This turn, the first pair part of an insert expansion sequence, is more aligned than PiC's previous 
response, and shows some willingness to negotiate by opening up a slot for $\mathrm{N}$ to take a turn that $\mathrm{PiC}$ may more readily align with - or resist even more strongly.

The next extract, from the very different environment of business-to-business 'cold' call telesales, nevertheless shows a similar pattern: a stepwise and delayed shift in stance from explicit rejection of the salesperson's nascent pitch for business. We join the call near the start, as the caller - the salesperson - formulates his reason for the call.

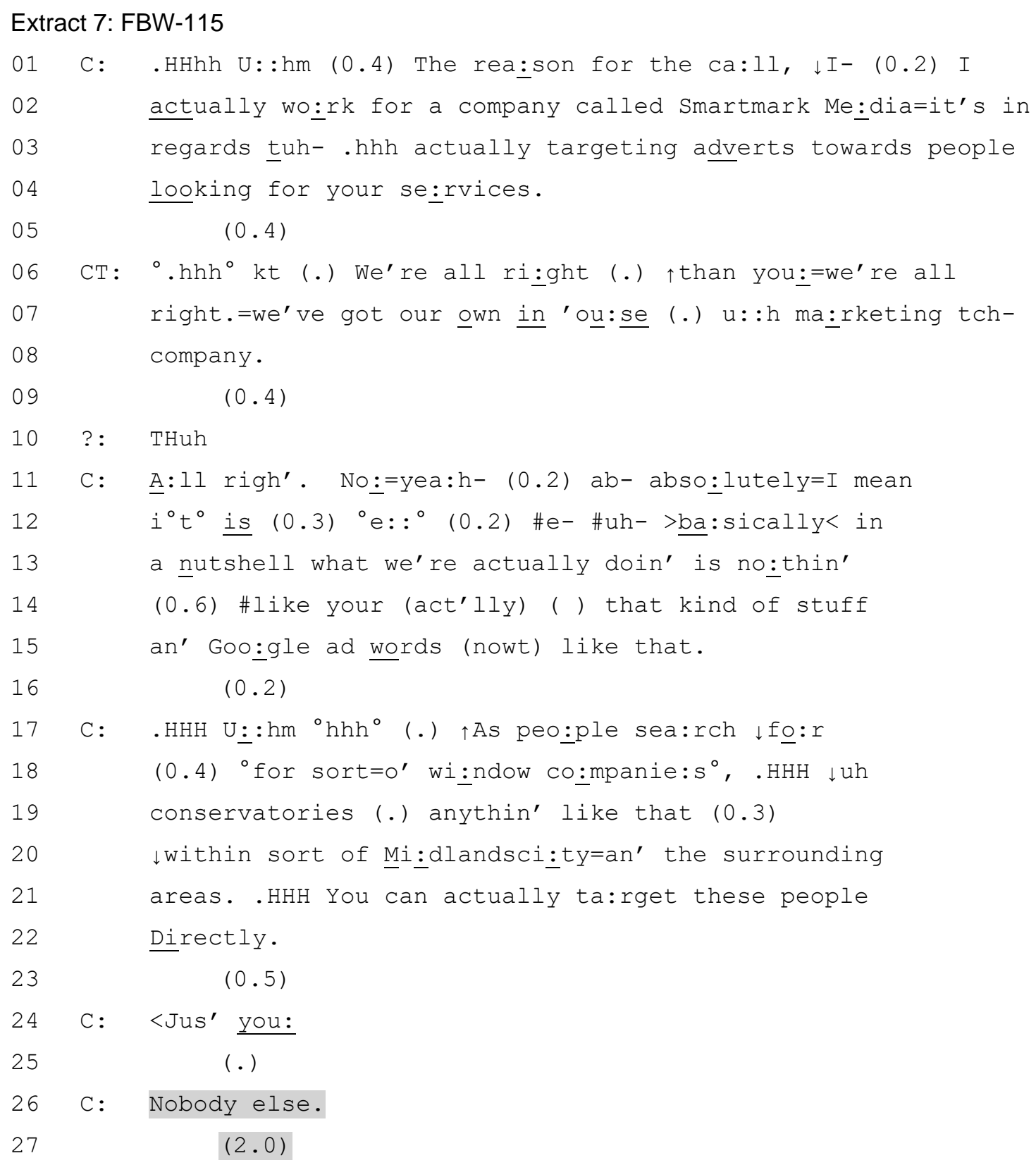




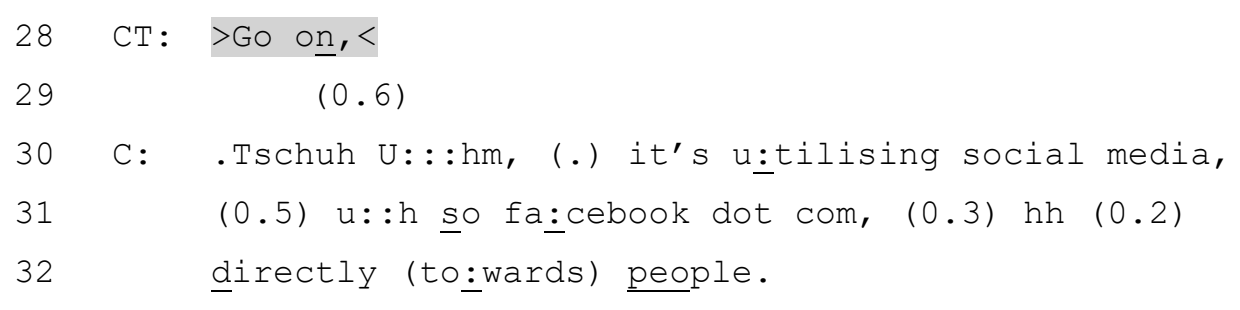

At lines 01-04, the salesperson describes what his company does, thereby formulating the reason for the call with a presentation of his company's services. In a place where the caller could show interest in their service, there is a 0.4 second gap (line 05). At line 06, the call-taker treats the caller's opening as initiating a sales pitch, and takes a turn designed to prevent the salesperson from pursuing the course of action initiated. In addition to the inter-turn gap, his turn begins with perturbations “o.hhh ${ }^{\circ} \mathrm{kt}$ (.)", further forecasting likely upcoming rejection. The dispreferred turn shape becomes more apparent when, following an appreciation of the nascent offer ("we're all right thank you"), the caller accounts for rejecting it ("we've got our own in 'ou:se (.) u::h ma:rketing tch- company."). In this way, the call-taker resists the presupposition in the salesperson's reason for call: he has no need for the service offered.

The salesperson acknowledges the call-taker's account for rejecting his services (“A:Il righ'. No:=yea:h- (0.2) ab- abso:lutely") but then goes onto challenge the basis of the call-taker's declination, by describing what his company does and does not do (lines 10-22). Note that, like the mediator in Extract 5, the salesperson takes several consecutive turns which receive no uptake (in this case, at lines 09,16, $23,25)$. At line 26 , the salesperson emphasizes the exclusive and specialized nature of their services that would help "nobody else" than the prospective customer. It is after this turn that the call-taker, after the longest delay in the sequence, produces a productive response (lines 27-28). He delivers the TCU itself, ">Go on<", rapidly. 'Go on [then]' is an almost idiomatic expression used to display a change of mind. Here, 
it functions as a 'go ahead' that allows the salesperson to present his offer (cf. "What for" in Extract 6). If the salesperson's turns constitute an offer or proposal, the calltaker's response is not a fully-fledged preferred one; it is not an acceptance. However, unlike previous turns in the extract, it is more closely aligned to the salesperson's course of action, which can now progress with this provisional (and notably delayed) response.

Extracts 4-7 demonstrate the stepwise progression from disalignment to (provisional) alignment between interlocutors. In each case, the initiating speaker (mediator, negotiator, and salesperson) pursues alignment - cashed out in terms of preferred and/or productive responses that progress a previously launched course of action. We noted that the responding parties' shifts in stance are delayed in sequential terms (by their remote position from any first action) as well as by silence and other markers of delay.

What is the purpose of delaying a response that is going to align with and progress the previous speaker's initiating action? Earlier in the paper, we presented a case that showed how delays provide "the person who initiated the sequence options to modify his or her prior talk or action" (Pomerantz and Heritage, 2012, p. 215-6), thereby minimizing the likelihood of a dispreferred response and orienting to the preference for, say, agreement, acceptance, and so on. Consider Extract 8, from the crisis negotiation dataset, in which $\mathrm{N}$ asks two wh-questions within one turn. After a long delay (line 03), the $\mathrm{N}$ and the PiC begin to talk at the same time, and $\mathrm{N}$ drops out of the overlapping talk.

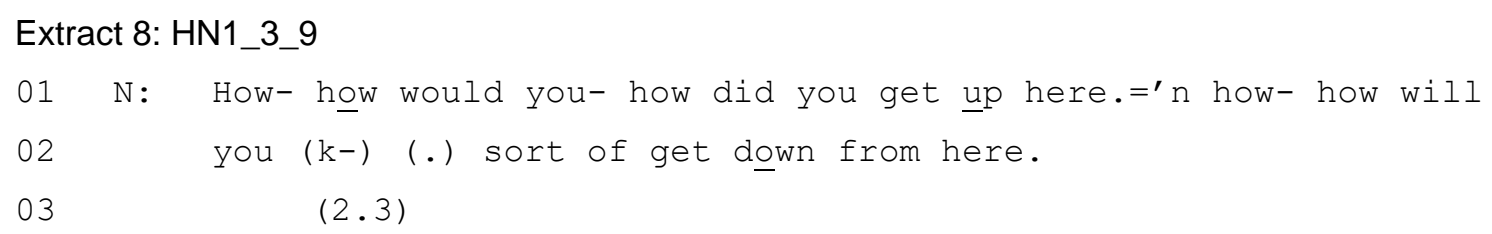


$04 \mathrm{~N}: \quad[\mathrm{Did}-\quad]$

05 PiC: [ I used] to climb up here when I was little.

That the negotiator begins to talk at line 04 is important for our analysis of delay; by starting a turn at line 04 , he treats 2.3 seconds (line 03 ) as an indication of upcoming dispreference - in this case, not producing an answer to his questions. However, at line 05 , the PiC in fact produces a preferred (in terms of action), albeit oblique response: an informing that serves as an explanation of how he might have climbed on the roof.

Given that, as it turns out, PiC responds to N's question before any modification has occurred, this delay indicates something other than upcoming disalignment, at least for PiC, if not $\mathrm{N}$. There are several possible reasons 'why' the delay occurs, then, and all are generally incompatible to a conversation analytic approach to interaction. We have already introduced one account from Goffman (1967): the maintenance of 'face' and a coherent public identity as someone who does not change their mind after adopting a previously strong intention or stance. Delaying the production of an aligned response after previous disaligned ones also, quite simply, breaks contiguity and temporally disconnects what one speaker says from what the other says. By delaying a preferred response, speakers may promote their footing equal with their interlocutor (Levinson, 1988); a subtle yet significant participatory stance towards the progressivity of the action under way. We also speculate that delaying a response that now agrees to meet a salesperson after stating one has no need for their products or agreeing with a negotiator to stay alive and not commit suicide are at the sharpest end of 'face' threats and not well-studied by social scientists and linguists. The notion that delaying productive responses promotes them as 'done reluctantly' fits 'face' theory, as well as done independently from the initiating action - that the responding party is deciding things for themselves, not 
because they have 'been persuaded'. Let us speculate momentarily on the latter account using Extract 9, which comes towards what will be the successful end of a crisis negotiation.

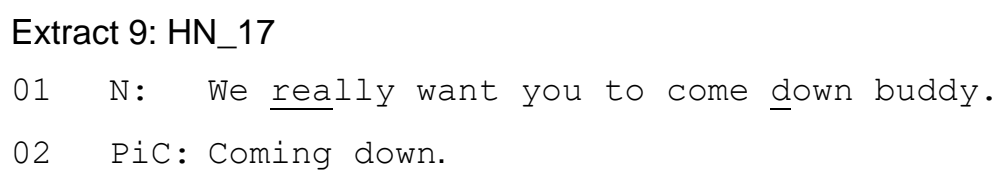

In none of our data does the potential client (in mediation and sales encounters) or person in crisis (in police negotiation and 911 calls), in their first turn, just agree to mediate, to an appointment, to 'come down', and so on. This is not surprising, but it is important. Extract 9 is implausible - almost laughable - if it was actually the entirety of the encounter. However, line 02 ("Coming down") is interesting in its design. At line $01, \mathrm{~N}$ 's request, with the inclusion of an urging 'really' suggests that $\mathrm{N}$ is not expecting PiC to comply immediately. However, PiC delivers an aligned response immediately; indeed, the strongest it can be. Note that, while PiC recycles 'come down' from N's turn, he does not repeat them, and his turn is grammatically designed as an assertion (it is an abbreviated version of 'l'm coming down'). It is, therefore, syntactically independent from N's turn (Stivers, 2005). PiC intends to come down, independently of and not occasioned by N's initiating action (rather than saying "Okay then", for instance).

Our final case comes from a call to 911 emergency services in the USA, from a caller who has reported that he is planning to jump off a bridge and that his girlfriend told him to call for help. As part of his narrative, he has told the dispatcher that his girlfriend is pregnant with his child and that he is depressed. 
Extract 10: Off the bridge

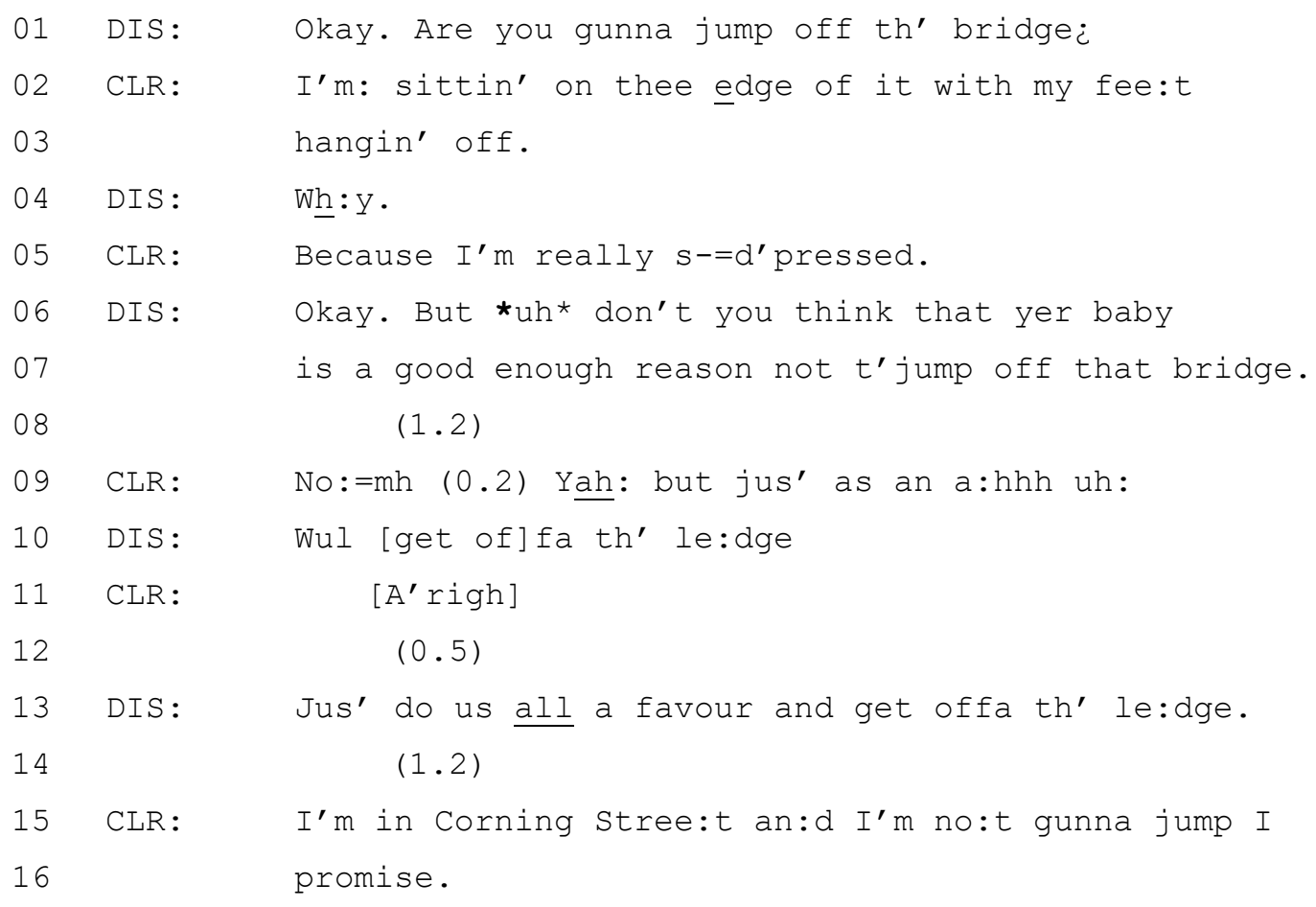

While the dispatcher works to get a definitive yes or no from the caller regarding his intention to jump (line 01), the caller produces a non-type confirming response (Raymond, 2003) by conveying that he is threatening to jump by dangling his feet off the edge. Our interest is in how the participants use the silence at line 08 and later in the sequence as a resource. The interactional problem is how the caller may agree to the dispatcher's terms without undermining the stance he has taken by threatening suicide.

Following the caller saying he is "really depressed" (line 05), the dispatcher appeals to the caller's logic about what it means to become a father as a way of coaxing him off the bridge. By framing her turn at line 06 with a negative interrogative, she asserts a position designed for strong agreement (Heritage, 2002). However, if the caller agrees with the dispatcher, he runs the risk of undermining his own project of threatening suicide. At line $08,1.2$ seconds of silence develop, which the dispatcher treats as belonging to the caller by giving him time to respond. When 
the caller speaks next, he starts with, "No:=mh" (line 09) and, by producing his talk with a sound stretch and nasal exhalation, he enacts a weakened rejection to the dispatcher's position. The caller then pauses, before producing a pro forma agreement "Yah: but jus"' (line 09), a marker of a disagreeing turn. However, the dispatcher takes advantage of her interlocutor's hesitations and continues to challenge the stance taken by the caller, a strategy we have shown to be effective (Sikveland et al, 2019).

In line 10, the dispatcher treats the caller's response as agreeing and asserts the upshot of what he should do next, "Wul get offa th' ledge". Just as the dispatcher says, "get off", the caller says, "A'righ" (line 11), agreeing to not jump. The silence at line 12, and the dispatcher's next move of prompting the caller, "Jus' do us all a favor and get offa th' le:dge." (line 13) provides some evidence that the dispatcher did not hear the caller saying "A'right." Following the dispatcher's turn, there is another long silence of 1.2 seconds where the dispatcher waits for the caller's response. After presumably agreeing not to jump (line 11), it would make sense for the caller to respond to the dispatcher immediately and without delay. Just after the delay, the caller's turn is not designed to respond to the dispatcher's directive to get off the ledge. While he shows a strong commitment not to jump, he takes control of the ongoing action by first giving his location (which he resisted earlier) and only then making explicit his commitment "I'm not gunna jump I promise". While this assertion aligns with the dispatcher's overall project of preventing the caller from jumping it is not fitted to her prior turn which had required him to get off the ledge. As such, the caller frames not jumping as an independent decision rather than an action he was coaxed into. 


\subsection{Discussion}

The aim of this paper has been to investigate episodes of interaction that deal with the core conversation analytic phenomena of 'preference organization' and related concepts of (dis)alignment and progressivity. The settings studied - mediation and telesales 'cold' inquiries; crisis negotiations; emergency service calls - share a particular interactional contingency: the participants have divergent stances at the start of the encounter. These initial disalignments result from one party not wanting or not seeking the help or service that is a core obligation of their interlocutor (e.g., not wanting the mediation that is offered; not initiating a sales call to buy a product but being requested to buy; not asking for help from negotiators) or/and by the interlocutors having a markedly different goal for the courses of action underway. These settings provided empirical materials that challenge an established finding that preferred responses - those that align and are productive for the progress of initiating actions - are typically delivered more rapidly than dispreferred responses which are projectable by delay, including inter-turn gaps. In the settings we studied, delay often preceded productive responses. That is, after rapidly produced turns that resist what is being proposed, offered, requested, and so on, by a first speaker, turns that then take a step towards agreeing to, being positive about, or aligning with the first speaker's course of action are preceded by delay. These actions include turns that are preferred in terms of function or overall action trajectory. Their delay, we suggest, attends to the 'face' threats associated with changing one's mind particular in cases where the change is from, for instance, committing suicide to saying alive. 
Our analysis showed that when one party in the conversation changes from a series of disaligned/dispreferred responses to the other party's actions, one resource that precedes and thus marks this change is inter-turn delay, or silence. We identified multiple instances of delayed productive responses in environments of potential or actual resistance to actions including requests, offers, proposals, and directives. We argue that the silence between first and second pair parts is an interactional resource that breaks the normative contiguity of turn-taking (Sacks, 1987), pushing back against the constraints of one action and giving an independent quality to the response, while not (or, no longer) explicitly resisting the course of action initiated previously. These findings dig further into the logic of delay and preference thus far observed in conversation analysis:

Delays function to provide a slot for revision inasmuch as they are interpretable as indexing the recipient's 'reluctance'. By enacting responses directly and with no hesitations versus with hesitations, mitigations and accounts, speakers can demonstratively index the extent to which they are committed to a point of view or course of action, and how that commitment fits with relational considerations (Pomerantz and Heritage, 2012, p. 217).

We have shown that in some interactional environments, in which stances are divergent and may (or may not) become aligned, delay functions to manage the 'face' concerns, or , as discursive psychologists put it, the 'subject side' concerns of speaker rationality and identity (Edwards, 2005). We argue that the delayed responses of potential clients or persons in crisis is not just about their reluctance to align with actions initiated by interlocutors, but also about managing a change of stance to a previously stated or embodied strongly resistant stance to do so, and 
previously displayed strong commitments to do the opposite of what interlocutors are trying to persuade them to do.

Our paper contributes to an emerging body of work on persuasive practices and resistance in conversation analysis and discursive psychology (Humă, Stokoe \& Sikveland, in press), which examines the turn-by-turn organization of what is more typically glossed in both academic (e.g., in psychology) and outside (e.g., in negotiation training manuals). For example, one of the most cited models for negotiation practice is the 'Behavioural Change Stairway Model' (BCSM) and its variant, the 'Behavioural Influence Stairway Model' (e.g., Vecchi, 2009). Developed by the FBl's Crisis Negotiation Unit, it outlines the relationship-building process involving the negotiator and subject, aiming to achieve a peaceful settlement of the critical incident (Vecchi et al. 2005). One of the core components of the model is 'active listening' and, within this, 'effective silence'. While this literature rarely states what constitutes such 'effective silences', we have been able to do so by observing the turn-by-turn development towards alignment in which professionals allow for inter-turn silences to unfold without, as our Extracts show, initiating self-repair.

Overall, we hope that this paper has shown the importance of examining the organization of talk in a wide range of settings, including extreme and high-stakes interaction which may be hard to access. The conversation analytic endeavour, to understand action in interaction, evolves as its methods and scope extend across environments, languages, settings, and modalities. In so doing, we continue to demonstrate how crucial it is to shed empirical light on the conversations that comprise everyday human action. 


\section{Funding}

The collection and preliminary analysis of the police crisis dataset was supported by the UK Metropolitan Police. The mediation dataset was collected as part of

Economic and Social Research Council grant "Identities in neighbour discourse:

Community, conflict and exclusion" (2005-2008) held by Elizabeth Stokoe and Derek Edwards.

\section{Acknowledgements}

We are grateful to our two anonymous reviewers for their thorough and constructive review of earlier drafts of this paper.

\section{References}

Bella, Spyridoula, and Moser, Amalia, 2018. What's in a first? The link between impromptu invitations and their responses. Journal of Pragmatics, 125, 96-110. doi.org/10.1016/j.pragma.2017.08.009

Bilmes, Jack, 1988. The concept of preference in conversation analysis. Language in Society, $17,161-181$.

Bilmes, Jack, 2014. Preference and the conversation analytic endeavor. Journal of Pragmatics, 64, 52-71. doi.org/10.1016/j.pragma.2014.01.007

Bögels, Sara, Kendrick, Kobin H., and Levinson, Stephen C., 2015. Never say no ... how the brain interprets the pregnant pause in conversation. PLOS ONE, 10(12), e0145474. doi.org/10.1371/journal.pone.0145474 
Bolden, Galina B., 2009. Beyond answering: Repeat-prefaced responses in conversation. Communication Monographs, 76(2), 121-143. doi.org/10.1080/03637750902828446

Boyle, R, 2000. Whatever happened to preference organization? Journal of Pragmatics, 32, 583-604.

Clayman, Steven E., 2002. Sequence and solidarity. In: Thye, S.R., and Lawler, E.J. (Eds.), Group Cohesion, Trust and Solidarity. Elsevier Science Ltd., Oxford, pp. 229-253.

Davidson, Judy A.,1984. Subsequent versions of invitations, offers, requests, and proposals dealing with potential or actual rejection. In: Atkinson, J.M. and Heritage, J. (Eds.), Structures of Social Action: Studies in Conversation Analysis, Cambridge University Press, Cambridge, pp. 102-28.

Edwards, Derek, 1997. Discourse and Cognition. Sage, London.

Edwards, Derek, 2005. Moaning, whinging and laughing: The subjective side of complaints. Discourse Studies, 7, 5-29. doi.org/10.1177/1461445605048765

Garcia, Angela, 1991. Dispute resolution without disputing: How the interactional organization of hearings minimizes argument. American Sociological Review, $56,818-835$.

Goffman, Erving, 1967. Interaction Ritual: Essays on Face-to-Face Behavior. New York: Doubleday.

Hepburn, Alexa, and Bolden, Galina B., 2017. Transcribing for Social Research. Sage, London.

Heritage, John, 2002. The limits of questioning: Negative interrogatives and hostile question content. Journal of Pragmatics, 34(10-11), 1427-1446. doi.org/10.1016/S0378-2166(02)00072-3 
Heritage, John, 2015. Well-prefaced turns in English conversation: A conversation analytic perspective. Journal of Pragmatics, 88, 88-104.

doi.org/10.1016/j.pragma.2015.08.008

Heritage, John, and Raymond, Geoffrey, 2005. The terms of agreement: Indexing epistemic authority and subordination in talk-in-interaction. Social Psychology Quarterly, 68(1), 15-38. doi.org/10.1177/019027250506800103

Heritage, John \& Sorjonen, Marja-Leena, 2018. Introduction. In Heritage, J., and Sorjonen, M-L. (Eds.), Between Turn and Sequence: Turn-Initial Particles Across Languages. John Benjamins, Amsterdam, pp. 1-22.

Humă, B., Stokoe, E. \& Sikveland, R.O. (in press.). Putting persuasion (back) in its interactional context. Qualitative Research in Psychology.

Jefferson, Gail, 1989. Preliminary notes on a possible metric which provides for a 'standard maximum' silence of approximately one second in conversation. In: Bull, Peter, Derek, Roger (Eds.), Conversation: An Interdisciplinary Approach. Multilingual Matters, Clevedon, pp. 166-196.

Jefferson, Gail, and Lee, John R.E., 1981. The rejection of advice: Managing the problematic convergence of a 'troubles-telling' and a 'service encounter'. Journal of Pragmatics, 5(5), 399-422.

Kendrick, Kobin H., and Torreira, Francisco, 2015. The timing and construction of preference: A quantitative study. Discourse Processes, 52(4), 255-289. doi.org/10.1080/0163853X.2014.955997

Kotthoff, Helga, 1993. Disagreement and concession in disputes: On the context sensitivity of preference structures. Language in Society, 22, 193-216.

Levinson, Stephen C., 1988. Putting linguistics on a proper footing: Explorations in Goffman's participation framework. In: Drew, P., and Wootton, A. (Eds.), Goffman: Exploring the Interaction Order. Polity Press, Oxford, pp. 161-227. 
Lindström, Anna, 2017. Accepting remote requests. In: Raymond, G., Lerner, G.H., and Heritage, J. (Eds.), Enabling Human Conduct: Naturalistic Studies of TalkIn-Interaction in Honor of Emanuel. A. Schegloff, John Benjamins Publishing Company, Amsterdam, pp. 125-143.

Margutti, Piera, Traverso, Véronique, Tainio, Liisa, and Drew, Paul, 2018. Invitations and responses: The formation of actions across languages. Journal of Pragmatics, 125, 52-61. doi.org/10.1016/j.pragma.2017.12.010

Pillet-Shore, Danielle, 2017. Preference organization. In: Nussbaum, J (Ed.), The Oxford Research Encyclopaedia of Communication. Oxford University Press, New York. doi.org/10.1093/acrefore/9780190228613.013.132

Pomerantz, Anita, 1978. Compliment responses: Notes on the co-operation of multiple constraints. In Schenkein, J. (Ed.), Studies in the organization of conversational interaction. Academic Press, New York, pp. 79-112.

Pomerantz, Anita, 1984. Agreeing and disagreeing with assessments: Some features of preferred/dispreferred turn shapes. In Atkinson, J.M., and Heritage, J. (Eds.), Structures of Social Action: Studies on Conversation Analysis, Cambridge University Press, Cambridge, pp. 57-101.

Pomerantz, Anita, and Heritage, John, 2012. Preference. In Sidnell, J., and Stivers, T. (Eds.), The Handbook of Conversation Analysis, Wiley-Blackwell, Oxford, pp. 210-228.

Raymond, Geoffrey, 2003. Grammar and social organization: Yes/no interrogatives and the structure of responding. American Sociological Review, 68(6), 939-967. doi.org/10.2307/1519752

Sacks, Harvey. 1987. On the preference for agreement and contiguity in sequences in conversation. In Button, G. \& Lee, J.R.E. (Eds.), Talk and Social Organization, Multilingual Matters, Clevedon, pp. 54-69. 
Sacks, Harvey. 1992. Lectures on Conversation (Vol I and II, edited by Gail Jefferson). Blackwell, Oxford.

Schegloff, Emanuel. A., and Sacks, Harvey, 1973. Opening up closings. Semiotica, 8(4), 289-327. doi.org/10.1515/semi.1973.8.4.289

Schegloff, Emanuel. A., 2007. Sequence organization in interaction. Volume 1. Cambridge, UK: Cambridge University Press.

Sikveland, Rein Ove, Kevoe-Feldman, Heidi, \& Stokoe, Elizabeth. (2019).

Overcoming suicidal persons' resistance using productive communicative challenges during police crisis negotiations. Applied Linguistics. DOI: doi:10.1093/applin/amy065

Sikveland, Rein Ove, \& Stokoe, Elizabeth. (2016). Dealing with resistance in initial intake and inquiry calls to mediation: The power of "willing". Conflict Resolution Quarterly, 33 (3), 235-253. DOI: 10.1002/crq.21157.

Steensig, Jakob, and Heinemann, Trine, 2015. The social and moral work of modal constructions in granting remote requests. In Drew, P. and Couper-Kuhlen, E. (Eds.), Requesting in Social Interaction, John Benjamins Publishing Company, Amsterdam, pp. 141-166.

Stivers, Tanya, 2005. Modified repeats: One method for asserting primary rights from second position. Research on Language \& Social Interaction, 38, 131-158.

Stivers, Tanya, 2008. Stance, alignment, and affiliation during storytelling: When nodding is a token of affiliation. Research on Language and Social Interaction, 41(1), 31-57. DOI: 10.1080/08351810701691123.

Stivers, Tanya, 2010. An overview of the question-response system in American English conversation. Journal of Pragmatics, 42, 2772-2781. doi.org/10.1016/j.pragma.2010.04.011 
Stivers, Tanya, \& Hayashi, Makoto, 2010. Transformative answers: One way to resist a question's constraints. Language in Society, 39(1), 1-25. doi.org/10.1017/S0047404509990637

Stokoe, Elizabeth. (2018). Talk: The science of conversation. London: Little, Brown. Stokoe, Elizabeth. (2013). Overcoming barriers to mediation in intake calls to services: Research-based strategies for mediators. Negotiation Journal, 29 (3), 289-314. DOI: 10.1111/nejo.12026

Vecchi, Gregory M., 2009. Conflict and crisis communication: The behavioral influence stairway model and suicide intervention. Annals of the American Psychotherapy Association, 12(2), 32-39.

Vecchi, Gregory M., Hasselt, Vincent B. Van, \& Romano, Stephen J., 2005. Crisis (hostage) negotiation: Current strategies and issues in high-risk conflict resolution. Aggression and Violent Behavior, 10(5), 533-51. doi.org/10.1016/j.avb.2004.10.001 